\title{
Dynamics of Human Pressures on the Mont Péko National Park (West-Côte d'Ivoire)
}

\author{
Ousmane Sidibe \\ Kouassi Kouadio Henri \\ Zadou Didie Armand \\ Kouame Djaha \\ Karidia Traore \\ University Jean Lorougnon Guédé, Daloa, Côte d'Ivoire
}

Doi: 10.19044/esj.2018.v14n11p109 URL:http://dx.doi.org/10.19044/esj.2018.v14n11p109

\begin{abstract}
The Mont Péko national Park (MPNP) located to the West of Côte d'Ivoire underwent severe human pressure related to a succession of political and military crises from 2002 to 2011. Since 2013, the Ivoirians government is engaged in a process of rehabilitation of this park. This study aimed to evaluate the dynamics of human pressures from 1996 to 2018, in order to allow the manager of the park to better focus their awareness and protection activities. To achieve this, the RAPPAM method of WWF international was adopted for the collection of data. The study identified 10 types of pressures of which farm is the most severe followed by pressure on land, logging, bush fires, the establishment of settlements, poaching and pollution. The intensity of pressures on the MPNP doesn't significantly vary depending on the areas, but this varies according to the socio-political gradient in time. The pressures have evolved gradually from 2002 to 2011 before beginning to decline progressively until 2018. Currently, except for uncontrolled bush fires, all pressures declined significantly, or even disappear for some. The existence of a variety of pressures on the MPNP to disturbing proportions is therefore related in part to the lack of monitoring during the crises. The anthropization of the MPNP found the springs of its acceleration in the existence of an armed gang who have organized, systematic exploitation of the resources.
\end{abstract}

Keywords: Armed conflicts, Human pressure, protected area, Mont Péko

\section{Introduction}

Since the beginning of the $\mathrm{XX}^{\mathrm{e}}$ century, tropical forests, which play a role in the water cycle, soil conservation, carbon sequestration and habitat protection, have been alarmingly degraded by a human pressures. (FAO, 
2016). The main concern raised is the loss of biodiversity as well as associated ecosystem goods and services, which is essential to the well-being of humankind. According to the work of FAO in 2010, there is a significant loss of forest area in South America and the African continent, respectively 4 and 3.4 million hectares per year.

In Côte d'Ivoire, the degradation of the forest heritage, under the weight of human activities, including farm and logging, dates back to the 1960s (Lanly, 1969). The network of protected areas covering about $10 \%$ of the territory (Lauginie et al., 1995a), was relatively less degraded, because of its strict protection by the state. Unfortunately, triggered political and military crises in 2002 led to the partition of the country and as a result the subtraction of some of these national heritages to the control of the state. Thus, these have been heavily infiltrated by the peasant populations, illegal loggers and poachers (UICN/BRAO, 2008 ; MINEDD, 2011). This resulted in an exacerbation of pressures on biodiversity in these protected areas which those located to the West of the country, particularly the Mont Péko national Park (MPNP). Indeed, the armed conflits beginning of 2000s until 2011, this park located in the area of belligerency between rebel groups and government administration and placed under control of the UN forces and French soldiers, cannot escape from numerous human pressures (Figure 1).

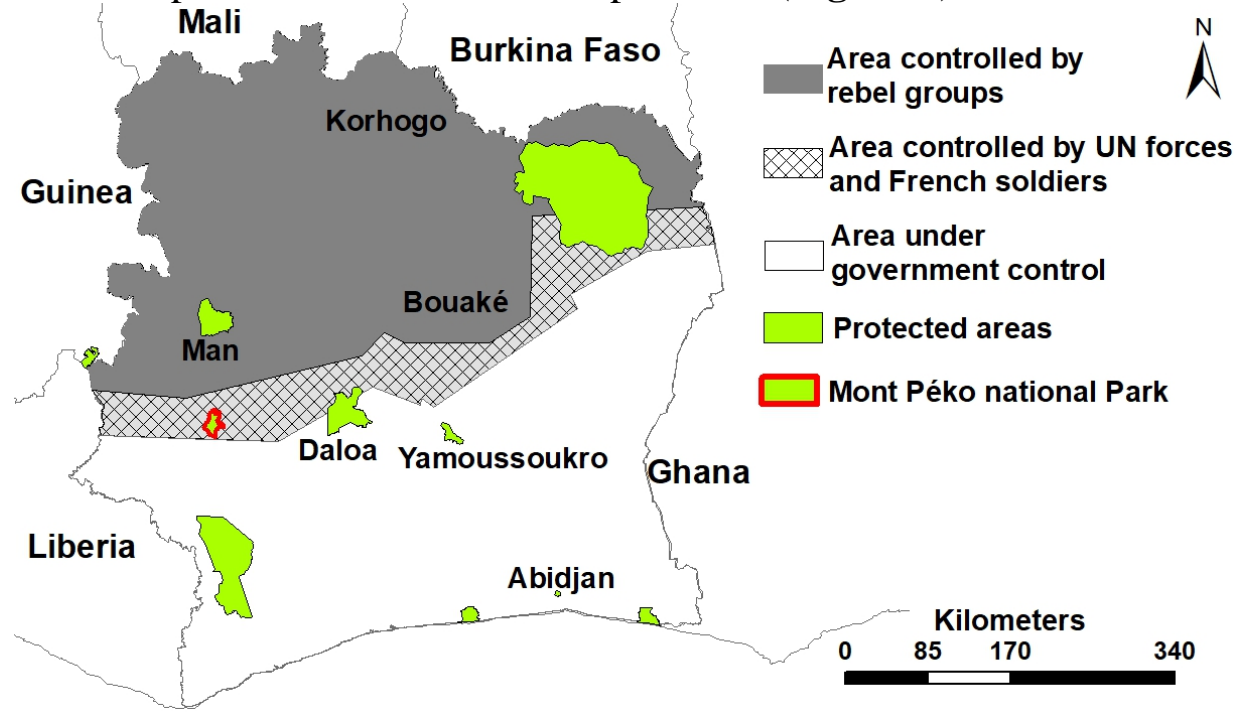

Figure 1. Location of the MPNP during the period of political and military crises from 2002 to 2011 in Côte d'Ivoire.

These pressures would significantly impact the biodiversity of the park (OIPR, 2013), now endangering this heritage. Faced with this situation, the government committed in the rehabilitation of the MPNP, right out of crisis. For this purpose, a vast operation to clearance of the people illegally installed 
in the park has begun in 2013 and is completed in 2016. In this process of rehabilitation, an assessment of the dynamics of pressures is necessary to allow the park manager to better focus their awareness and protection activities. However, this subject remains little explored. This study proposes to fill this gap by assessing the dynamics of pressures on the MPNP from 1996 to 2018 which covers periods of before crisis to after crisis. It is based on the hypothesis that the amplification of the human pressure on the park was due to periods of armed conflicts. It concerned to identify the types of human pressures on the MPNP and analyze the dynamics of the degree of these pressures before, during and after crisis.

\section{Methods}

Study area

The MPNP is located in the West of Côte d'Ivoire (Figure 2), between $6^{\circ} 53^{\prime}-7^{\circ} 08^{\prime}$ of latitude north and $7^{\circ} 11^{\prime}-7^{\circ} 21^{\prime}$ of longitude west. It covers an area of 34000 hectares and belongs to the administrative departments of Duékoué and Bangolo. The park is characterized by undulating plateaus of 300 to 500 meters of altitude in his South area and three well individualized peaks, whose highest is Mont Péko in its northern area. The vegetation consists of dense moist semi-deciduous forest with secondary vegetation resulting from agricultural activities (Monza, 1996). The climate is humid with two rainy seasons. The rainy season occurs from March to October and the long dry season lasts from November to February.

\section{Data collection}

The methodology used for data collection is inspired from the RAPPAM (Rapid Assessment and Prioritization of Protected Area Management) method of WWF (Ervin. J., 2003). To do this, the questionnaire of the RAPPAM method related to the assessment of the pressures on a protected area was adapted to a socio-political gradient of different connotations (period of before, during, and after crisis). The elaboration of the questions has been guided by local understandings. These were filled in the course of a participatory workshop implicating agents of the Ivorian Office of Parks and Reserves (OIPR), members of the Monitoring Committee Villagers (CVS), a local NGO "CODEPARC", ex-infiltrated of the park and a team of researchers of the University Jean Lorougnon Guédé (Figure 3). 


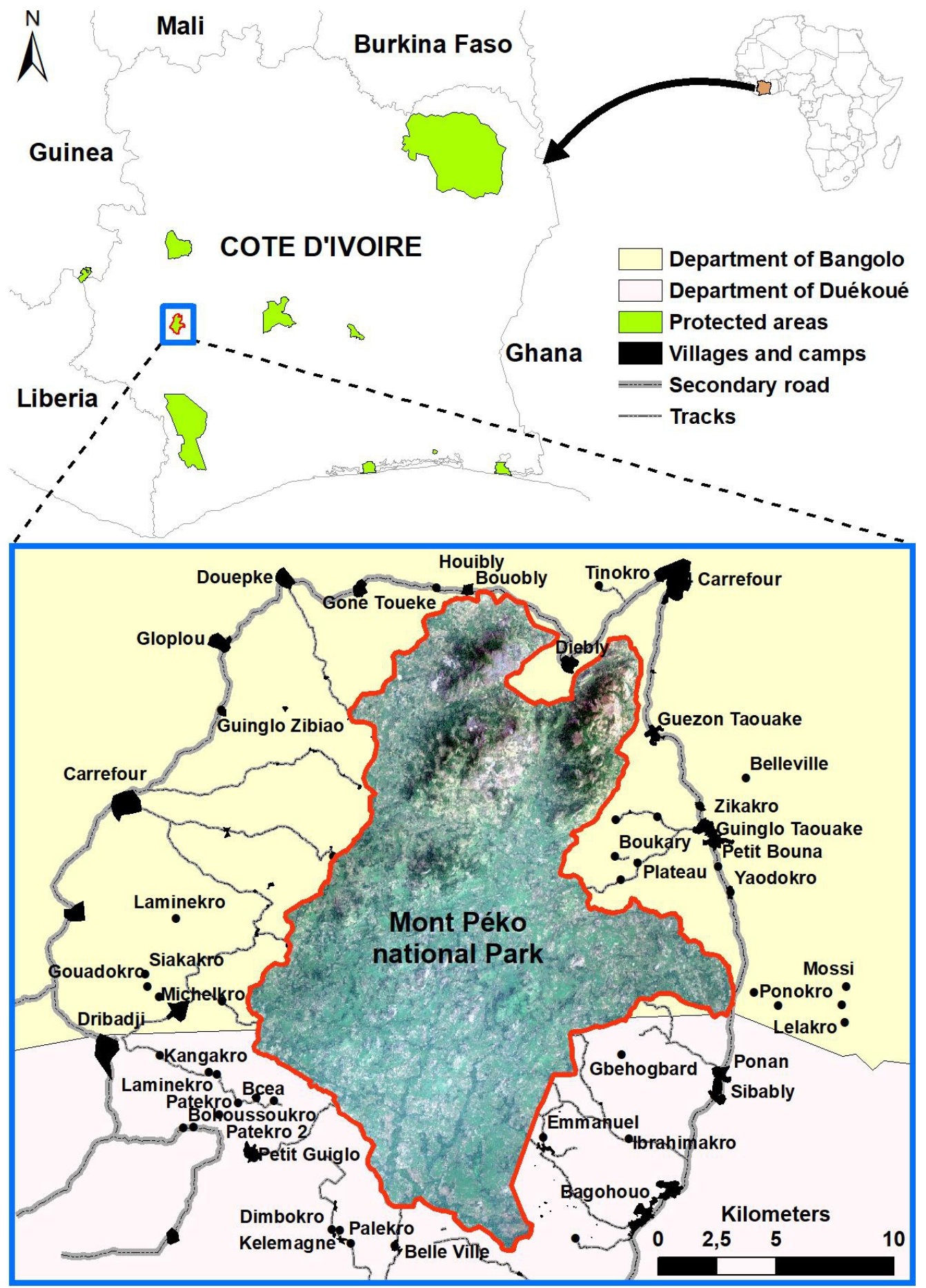

Figure 2. Location of the MPNP in the western part of Côte d'Ivoire. 

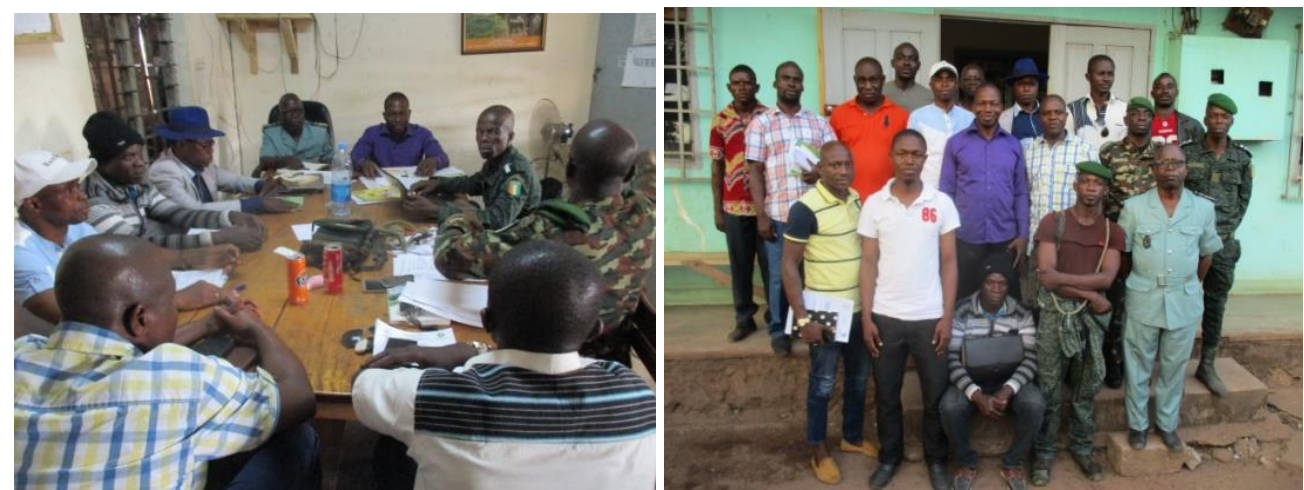

Figure 3. Opening ceremonies of the workshop (left) and family photo ending the session (right).

During this workshop, the park has been split in two, taking into account its geomorphology (Figure 4). The questions were administered on the basis of the identified pressures and crisis fluctuations in the area from 1996 to 2018.

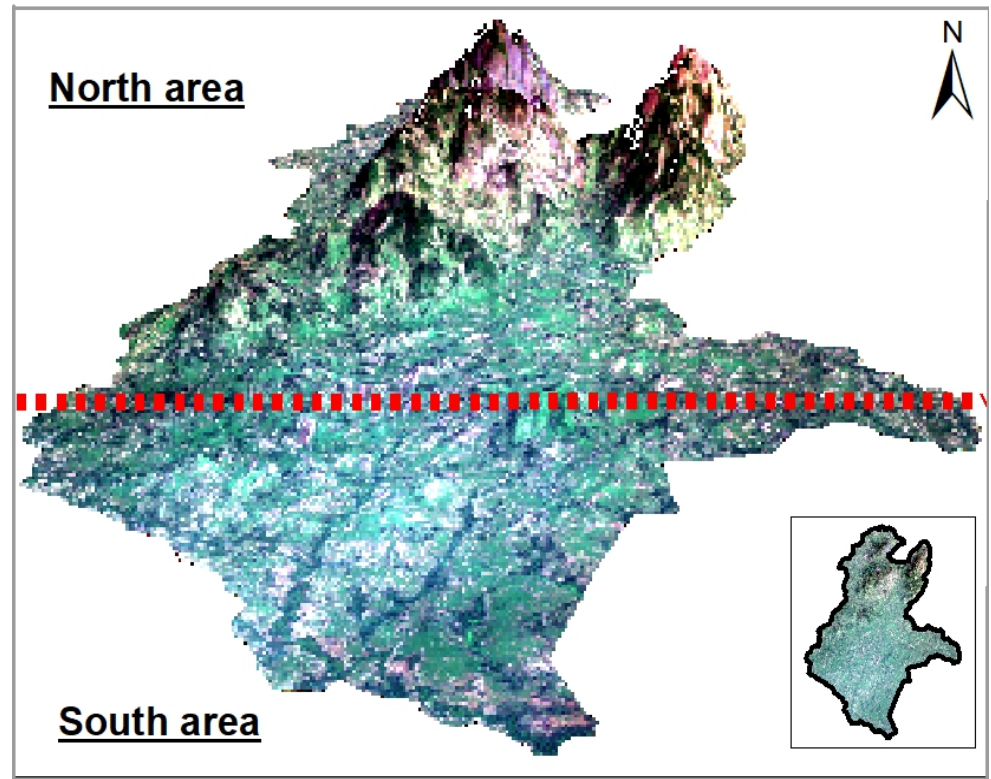

Figure 4. Presentation of the zonation of the MPNP in this study.

\section{Analysis of the data}

The responses to specific questions in the questionnaire have been encoded according to a scale of 1 to 4 as follows: extent localized (1), scattered (2), wide dispersion, (3) or throughout (4); impact bit harsh (1), moderate (2), strong (3), or severe (4); duration in the short term (1), medium term (2), to very long term (3) or permanent(4). The degree of each pressure is the factor of these three elements. For example, a pressure which has a wide 
dispersion (3), a moderate impact (2) and has a period of recovery in the short term (1), will have a score of $6(3 \times 2 \times 1)$. Each pressure can have a score between 1 and 64. A score between 1-3 is considered low, between 4-9 moderate, between 12-24 high and between 27-64 severe. The degree of pressure of each type of human activity illegal in the MPNP was determined according to the areas and well defined periods. A distribution of scores for each pressure by area and at the time was made. To assess the influence of the periods of crises and the geomorphology on the dynamics of different types of pressures, different scores calculated by area and time period were investigated through an analysis of variance (ANOVA) to two factors. For the significant probability, Tukey's HSD (honest significant difference) test has been applied for the categorization of the averages. Statistical analyses processing were done using STATISTICA 7.1 software.

\section{Results}

\section{Types of pressures on the Mont Péko national park (MPNP)}

Throughout the periods studied from 1996 to 2018, ten types of pressures on the MPNP have been identified (Figure 5).

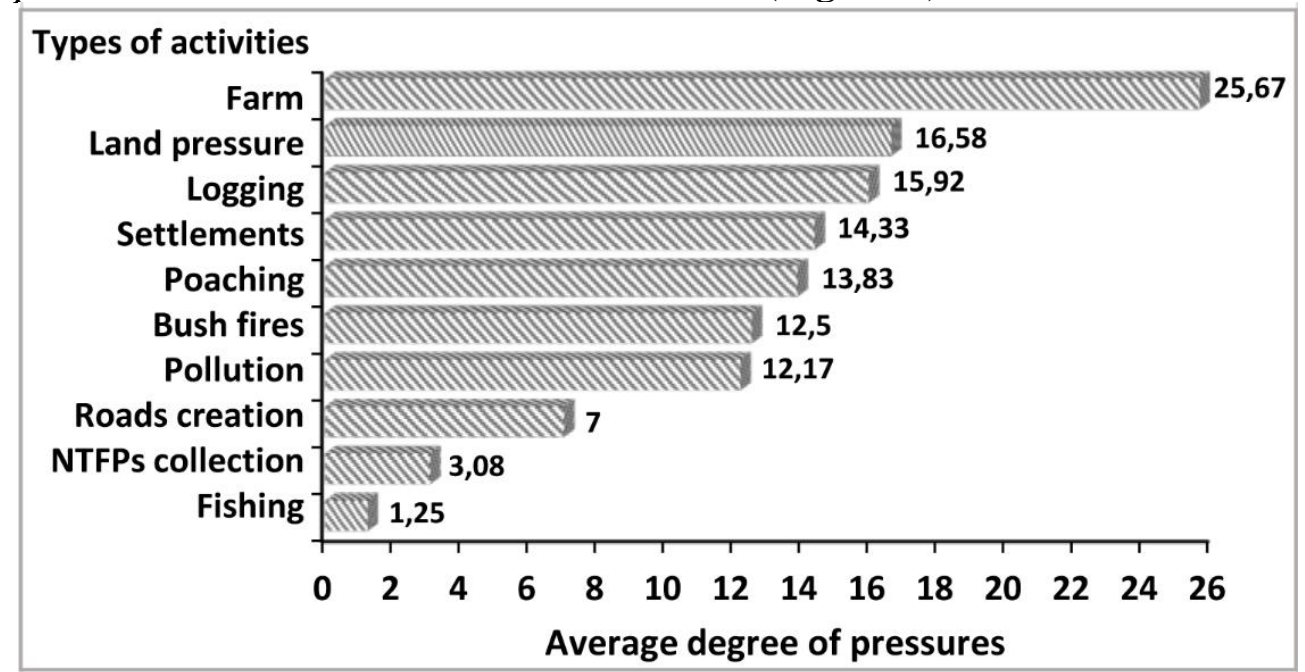

Figure 5. Proportion of the average degree of pressure of the types of illegal activities in the MPNP from 1996 to 2018.

The farm with an average degree of pressure 25,67 is pressure severe in the MPNP, followed by the land pressure which dates back to the years 1974 , with the wrong bordering of the boundary of the creation decree $\mathrm{N}^{\mathrm{O}} 68$ 79 February 09, 1968. This boundary called «boundary Goué » gives the MPNP area 28581 hectares instead of 34000 hectares such as provided for by the decree of creation, where a real confusion in the field as to compliance with it (Figure 6). 


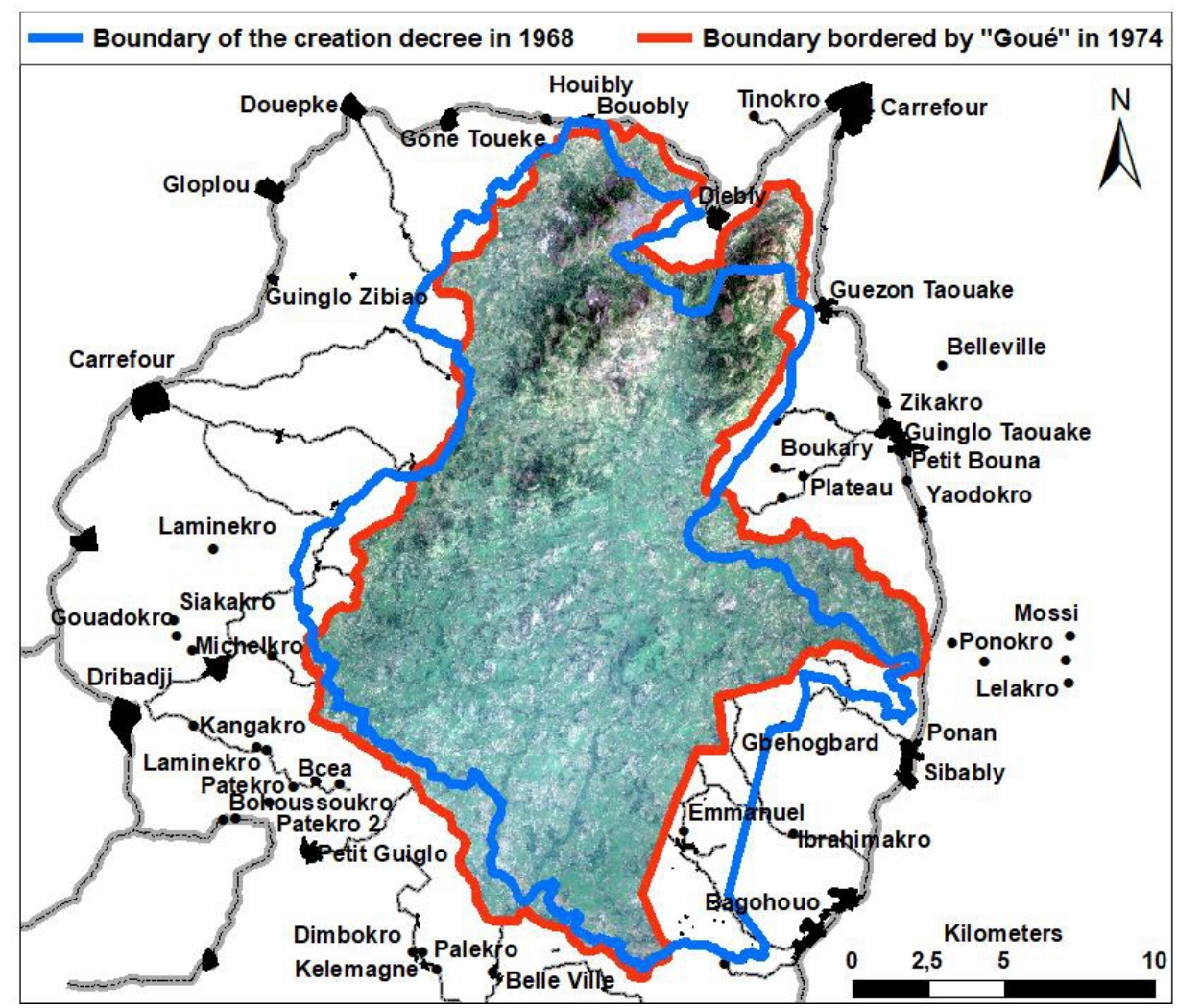

Figure 6. Illustration of the confusion of the MPNP Boundary.

Logging, uncontrolled bush fires, the establishment of settlements, poaching and pollution of soils or the environment through the use of pesticides, with respective average pressures scores of 16,$58 ; 15,92 ; 14,33$; 18,$33 ; 12,5$ and 12,17 are also reached degree of high pressures. The creation of roads and tracks with a medium degree of pressure equivalent to 7 is a moderate pressure. With pressure levels oscillating approximately between scores 1-4, the collection of non-timber forest products (NTFPs) and fishing are the types of low pressure in the MPNP.

In short, from 1996 to 2018 the farm is by far the greater pressure in the MPNP followed by pressure on land, logging, bush fires, the establishment of settlements, poaching and pollution of soils or the environment. The area south of the park suffered 51\% of these pressures and 49\% North area (Figure 7). 


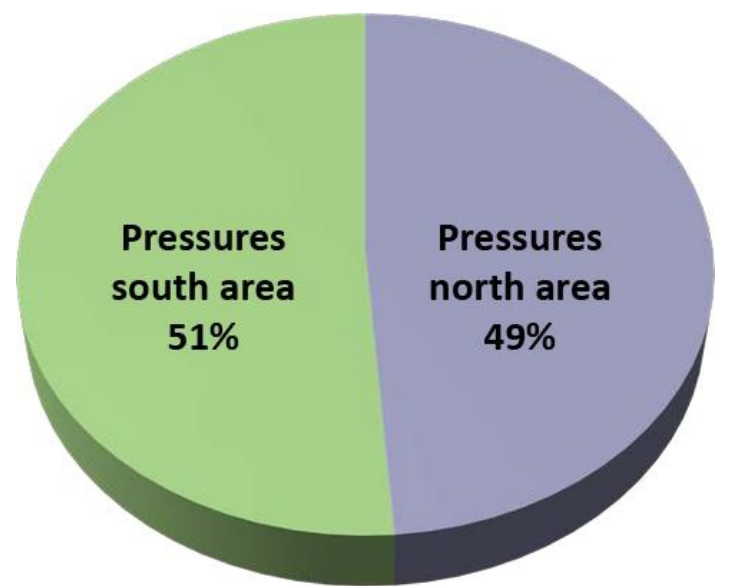

Figure 7. Proportion of pressure in the areas south and north of the MPNP from 1996 to 2018.

Distributions of the degree of pressure in areas north and south of the MPNP in time

The distribution of degree of severity of different identified pressures vary area north to the South of the MPNP area, over time (Figure 8).

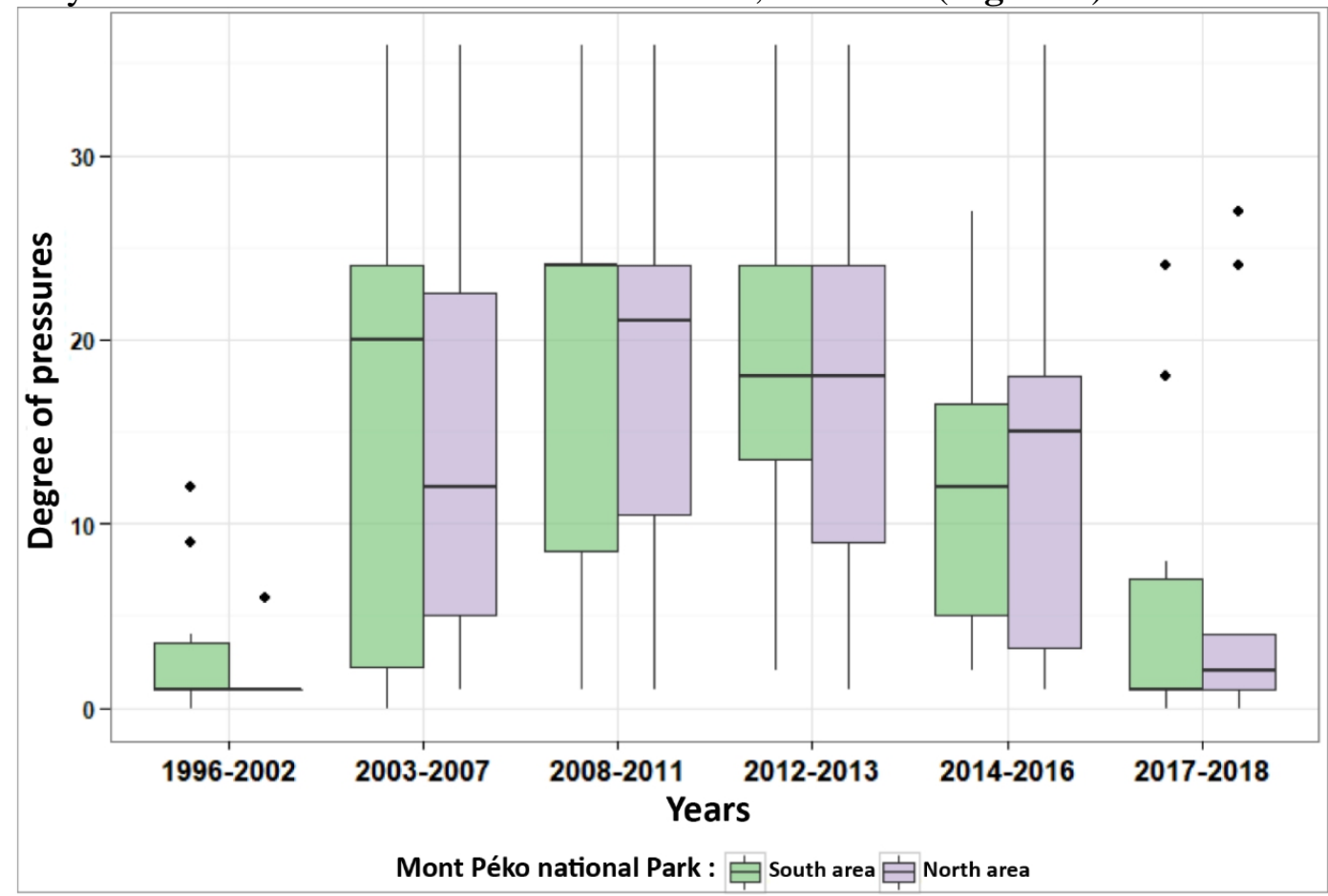

Figure 8. Diachronic comparison of the distributions of the degree of pressures in the areas north and south of the MPNP from 1996 to 2018. 
However, two factor ANOVA analyze indicates the degree of pressures do not vary by area (ANOVA, $\mathrm{F}=0.106, \mathrm{P}=0.745$ ). But this analysis indicates that the variance of the degree of pressures based on the periods studied is very significant (ANOVA, $\mathrm{F}=8.355, \mathrm{P}=0,00000105$ ). Based on this significant probability, the separation of $\alpha=0.05$ level averages of Tukey's HSD test, allow to discriminate the degree of pressures distribution in time into four classes (Table I). The first class consists of the 1996-2002 period, the second class by periods of 2003-2007; 2008-2011 and 2012-2013, the third class by the 2014-2016 period and the fourth class by $2017-2018$ period.

Table I: degree of average pressure at different times on the MPNP.

\begin{tabular}{|c|c|}
\hline Periods & Average degree of pressures \\
\hline $1996-2002$ & $2,6 \mathrm{~b}$ \\
\hline $2003-2007$ & $15,5 \mathrm{a}$ \\
\hline $2008-2011$ & $18 \mathrm{a}$ \\
\hline $2012-2013$ & $17 \mathrm{a}$ \\
\hline $2014-2016$ & $12 \mathrm{ac}$ \\
\hline $2017-2018$ & $6,25 \mathrm{bc}$ \\
\hline
\end{tabular}

NB: The same letter is assigned to the various averages constituting a class. Different letters are assigned to two different classes.

\section{Dynamics of pressure in different areas of the MPNP in the course of the time}

Figure 9 shows that the curve of the degree of pressures based on the time looks the same in the areas north and south of the MPNP. But from 1996 to the first half of 2013, the degree of pressures in the South area are higher than those of the North, unlike the period from the second half of 2013 to 2018. Overall, the degree of severities of pressures have increased from 2002 to 2011. This increase was very strong between 2007 and 2011. However, the degree of severities of the pressures decreased from 2012 to 2018. Nevertheless, between 2012 and 2013, the reduction in degree of pressures remained low. 


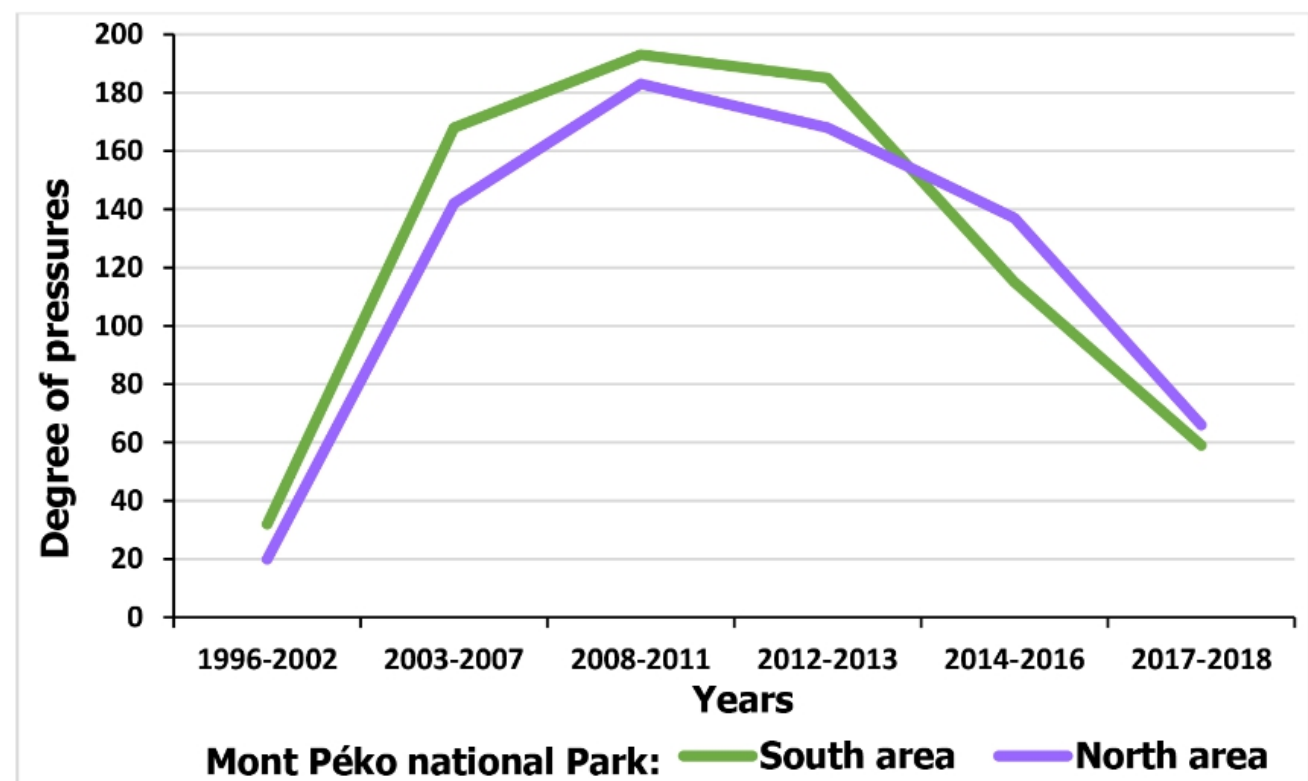

Figure 9. Evolution of the degree of pressures in the North and South of the MPNP areas over time.

Evolutionary trends of the degree of pressures from different types of human activities vary according to the time in areas north and south of the MPNP (Figure 10). In this figure, we can discriminate against the evolutionary trends of the degree of the different types of pressure into 3 groups. Group 1 to bimodal evolutionary trend that are convex: farming, logging, poaching, land pressure, pollution, the establishment of settlements, the creation of roads and tracks and the collection of NTFPs. However, we notice the evolutionary trend of the degree of pressures from farming in the North area has largely taken the upper hand over the area south from mid-2013 until 2018. It's the same for the collection of NTFPs that begins to decline from 2018. Group 2 includes fishing in the South and North of the MPNP area, to respectively a mixed evolutionary trend bimodal convex and singlemode constant. Group 3 with mixed evolutionary trend: monomode growing and monomode decreasing, is composed respectively of uncontrolled bush fires in areas south and north of the park.

In total, currently, except uncontrolled bush fires, all pressures declined significantly, or even disappear for some such as logging, the establishment of settlements, the creation of roads and tracks, pollution of soils and the environment through the use of pesticides. 


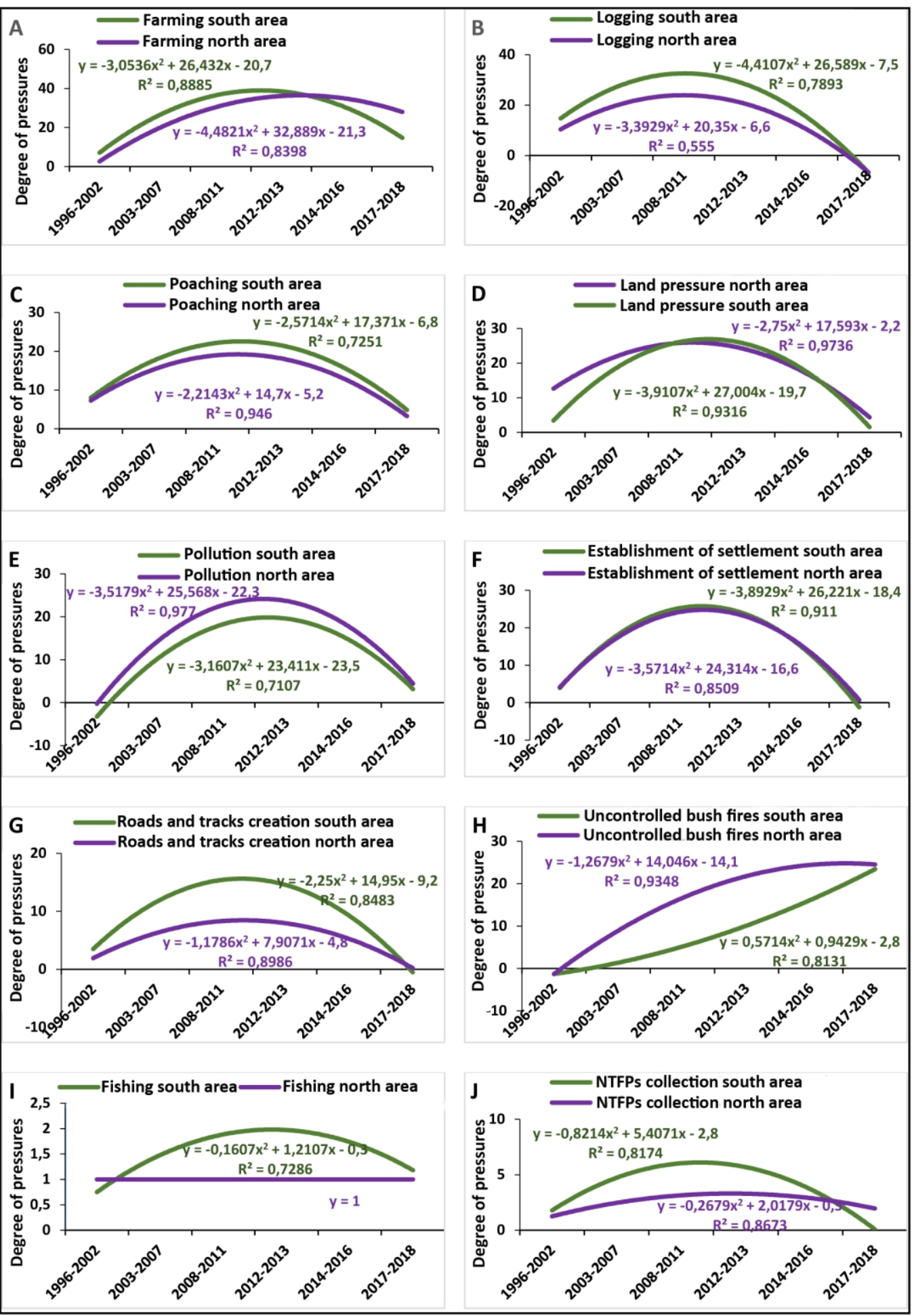

Figure 10. Changing patterns compared the severity of different types of pressures in the areas north and south of the MPNP according to time. 


\section{Discussion}

\section{Types of pressures on the Mont Péko national Park (MPNP)}

The MPNP is generally subject to various forms of pressure with degree of varying severities. Just like Assalé et al (2016), in the Haut Sassandra Classified Forest, mentioned, the farm is by far, the pressure that causes severe damage to the natural resources of the MPNP. Indeed, the practice of this speculation in the majority of the West African soils is characterized by slash and burn agriculture, wood craft cup and the stumping by fire as a gateway (Monnerat et al., 2014). Prior to 2002, the agricultural pressure was essentially due to native people « Guéré » on the outskirts of the park. It consisted of the creation of some plantations of coffee and cocoa (Akindès, 1996). After 2002, there has been the creation, large-scale, planting of cocoa and associated crops (yams, taro, rice, but etc.) in the Center of the park. This agricultural intensification has been for corollaries, the creation of settlements, roads, tracks and soil or pollution of the environment through the use of pesticides, which have also caused significant damage to natural resources of the MPNP. Poaching and uncontrolled bush fires have always existed in the area. But the lack of monitoring and the anthropization of the park would have accentuated these phenomenons. Clandestine, the MPNP was already the subject of collection of wood before 2002. However, with the departure of the officers serving in the park because of the crisis, this illegal activity would have been intensified by sawmills located in Duékoué area and further in San-Pédro and Daloa, through armed gangs. Land pressure in the MPNP, pulls these roots of confusion boundary generated by the wrong bordering of 1974. Residents still respect the boundary that allows them to acquire more portions of land. But overall, the boundary of 1974 « boundary Goué » is the most respected in the area. However, with control of the park during the crisis by armed gangs, this pressure on land is transformed into occupations of the park for purposes of cocoa production. According to a report of the Ivorian government, the total population who lived there was 27045 people, with $4 \%$ of the occupants of Ivorian origin and $96 \%$ of foreign origin which $99 \%$ of Burkina Faso (APA, 2013). After the total clearance of the park by OIPR in 2016, a project of redefinition of the boundary of the decree of creation of 1962 is in course of development in order to settle the problem of boundary. Currently, the shrinking of farming land, the population explosion, sprawl and densification of settlements goshawks of the park are factors that reinforce this pressure. Also, the results of this study showed that logging have reached a degree of high pressure in the MPNP. This result is similar to that of the assessment by the IUCN/BRAO (2008), in Côte d'Ivoire. Unlike other types of pressures, the intensity of the collection of NTFPs is moderate and fishing is low in the park. Indeed, according to the results of the study of IUCN/BRAO (2008), these pressures are not specific to the MPNP 
compared to the Banco national Park (strong collection of NTFPs and woody secondary to the pharmacopoeia) and the Comoé national Park (degree of fishing very high). The existence of a variety of human pressures on the MPNP to disturbing proportions is related in part to the lack of monitoring during the crisis. Pressure rate approximately equal in areas north and South (59\% and $49 \%$ ), according to the results of the study, indicates a generalization of the anthropization of the park.

\section{Evolution of pressure in different areas of the MPNP in the course of the time}

The results of the study showed that the degree of pressure on the MPNP vary depending on periods of study from 1996-2002, 2003-2007, 20082011; 2012-2013, 2014-2016 and 2017-2018. From 1996 to 2002, the MPNP recorded low degree of pressure of the fact of its surveillance. However, the increase in the pressure levels from 2003 to 2007 (after the socio-political crisis of 2002) and more of 2008 to 2011 (during crisis) and from 2012 to 2013 (period post-crisis election) is related to the lack of MPNP monitoring during these periods of crises. The anthropization of the park found the springs of its acceleration in the existence of an armed gang who could have organized the systematic exploitation of the resources of the protected area. The reports of MINEDD (2011) and OIPR (2013) highlight this state of facts. As for the decrease of the degree of pressures, first phase of decline in 2014 to 2016 (period post-crisis) is relatively less marked, because the park was still under the influence of an armed gang. However, the regression of the pressure during this period could be attributed to the cumulative effects of several factors including, socio-political stability that had been recently reached, neutralization in 2013 of the armed gang who controlled so far the park and the beginning of the activities of the forestry administration. At this level, the activities of the OIPR consisted to sensitization to a clearance of and arrests of loggers in the vicinity of the park, because of the insecurity that prevailed there. The second phase of pressure decline observed over the period from 2017 to 2018 is probably due to the total expelling clandestine populations from the MPNP in 2016 and the real beginning of the OIPR management activities.

Currently, except for uncontrolled bush fires, all pressures declined significantly, or even disappear for some such as logging, the creation of settlements, the creation of roads and tracks, pollution of soils or the environment through the use of pesticides. Certainly, these fires can have natural origins, especially those in the North, during periods of drought acute on the flanks of the mountain because of the very high temperatures that prevail there, but the hypothesis of criminal fires of revenge on the part of clear of people who prowl around the park is very plausible. 
Furthermore, of the fact of the presence of thousands of hectares of cacao plantations abandoned in the park, the farm remains the main threat. Indeed, some clear of people still infiltrate illegally the park for picking cocoa and food. The reports of the daily monitoring of the OIPR demonstrates several arrests in the park on this subject. As a deterrent and planning for now, OIPR has implemented an operation of cutting of the feet of cocoa.

\section{Conclusion}

The Mont Péko national Park is subject to strong human pressure likely to compromise its ecological integrity. The study identified 10 types of pressures of which farm is by far the most severe followed by pressure on land, logging, bush fires, the establishment of settlements, poaching and pollution of soil or the environment through the use of pesticides. The intensity of pressures on the MPNP doesn't significantly vary depending on the areas, but this varies according to the socio-political gradient in time. These pressures, of weak intensity before 2002, have increased after the September 2002 political and military crisis that has shaken Côte d'Ivoire and intensified still further in the wake of the post-election crisis in 2010 until 2013. In this dynamic, logging, would have served as a catalyst in the sense that it has facilitated, the clearances. The anthropization of the park found the springs of its acceleration in the existence of an armed gang who have organized, systematic exploitation of the natural resources.

However, the exit from crisis in 2011 and the operation of expelling clandestine populations from the MPNP initiated by the state of Côte d'Ivoire in 2013, have helped significantly to reduce all forms of human pressures on the park, or even disappear for some. On the other hand, uncontrolled bush fires are up because of factors endogenous and exogenous are: prolonged drought due to climate change and the public-spiritedness of people who always looking for plots of crops. Therefore, this pressure merit special attention on the part of the OIPR in order to limit the scourge in a near future. In order to consolidate the achievements, existing monitoring mechanism should be strengthened through the provision of additional funding to the manager and the problem of boundary of the park must attract special attention from local authorities and national.

\section{Acknowledgements}

The authors thank the Strategic Support Programme for Scientific Research in Côte d'Ivoire (PASRES) for the financing of this study through the project «Impact of the decade of political and military crisis on the dynamics of the flora and vegetation of the Mont Péko national Park in Côte d'Ivoire ». Also the authors thank the African Center of Excellence in climate change, biodiversity and Sustainable Agriculture (CEA-CCBAD) for offering 
a framework and support for the PhD student Ousmane SIDIBE through its training program $\mathrm{PhD}$ Climate Change and Biodiversity. Also, the authors thank the Ivorian Office of Parks and Reserves (OIPR) who has authorized access to the Mont Péko national Park and support missions on the ground.

\section{References:}

1. Akindes, F. (1996). Etude pour le renforcement de la protection et l'aménagement du Parc national du Mont Péko; aspects socioéconomiques. MINAGRA/PARC-CI, Abidjan, 79 pp + annexes.

2. APA, (2013). «96\% des occupants du Mont Péko sont d'origine étrangère ", selon un rapport du gouvernement ivoirien. Abidjan.net, 13, 11-2013. Recuperé de http://www.news.abidjan.net/h/479973.html.

3. Assale, A. A. Y., Barima, Y. S. S., Kouakou, K. A., Kouakou, A. T. M., \& Bogaert, J. (2016). Agents de dégradation d'une aire protégée après une décennie de conflits en Côte d'Ivoire: cas de la forêt classée du Haut-Sassandra. Int. J. Innov. Sci. Res, 22 (1) 123 - 133.

4. Ervin, J. (2003). Rapid Assessment and Prioritization of Protected Area Management (RAPPAM). Gland (Switzerland): World Wide Fund for Nature.

5. FAO, (2010). Evaluation des ressources forestières mondiales 2010. Rapport principal. Organisation des Nations Unies pour l'alimentation et l'agriculture, Rome, $377 \mathrm{p}$.

6. FAO, (2016). Situation des forêts du monde 2016. Forêts et agriculture: défis et possibilités concernant l'utilisation des terres, Rome, $137 \mathrm{p}$.

7. Lauginie, F., Béligné, V., Akindes, F., \& Poilecot, P. (1995a). Monographie des réserves naturelles de Côte d'Ivoire. DDC/MINAGRA/WWF, Abidjan, 178 p.

8. Lanly, J-P. (1969). La régression de la forêt dense en Côte d'Ivoire. Bois et forêts des tropiques. ${ }^{\circ} 127$ :45-59. In GUILLAUMET, J.-L., \& ADJANOHOUN, E., La végétation de la Côte d'Ivoire. pp. 155261.

9. MINEDD, (2011). MAG / Grands Dossiers / $N^{\circ}$ 001, Ministère de l'environnement et du développement durable, Abidjan, Côte d'Ivoire.

10. Monnerat, M., \& Tchatchou, B. (2014). Foresterie urbaine et agroforesterie pour l'adaptation et l'atténuation à Lukolela., Center for InterNational Forestry Research (CIFOR), Bogor, Indonesia.

11. Monza, J-P. (1996). L'Atlas pour la conservation des forêts tropicales d'Afrique. UICN, $310 \mathrm{p}$. 
12. OIPR, (2013). Rapport sur l'appui à la direction de zone Ouest dans le cadre de l'apurement du Parc national du Mont Péko, Ministère de l'environnement, Duékoué, Côte d'Ivoire, $8 \mathrm{p}$.

13. UICN/BRAO, (2008). Evaluation de l'efficacité de la gestion des aires protégées: parcs et réserves de Côte d'Ivoire, $43 \mathrm{p}$. 